\title{
Digital Assessment Literacy: The Need of Online Assessment Literacy and Online Assessment Literate Educators
}

\author{
Farhat N. Husain ${ }^{1}$ \\ ${ }^{1}$ Quality for Excellence for Education Consultancy, Kingdom of Bahrain \\ Correspondence: Farhat N. Husain, Quality for Excellence for Education Consultancy, Kingdom of Bahrain.
}

Received: April 26, 2021

Accepted: June 10, $2021 \quad$ Online Published: September 18, 2021

doi:10.5539/ies.v14n10p65

URL: https://doi.org/10.5539/ies.v14n10p65

\begin{abstract}
Creation of reliable online assessments have always been a concern by educators, this research article provides an idea for providing professionals training development for creating online assessments for the inexperienced assessment literate teachers. The research has placed the importance on the training of the educators in the assessment literacy with a proposed model of utilization of Educational framework to create digital online assignments using IT integrated tools. This paper uses mixed method research and examines the need of training for the creation of reliable assessments and assessment literate educators which will caters to the different students' abilities. To further explore and understand the training needs of the assessment literacy, this research provides an insight of the year 2020 result analysis, as it might add a new dimension towards the professional development for the online assessment literacy skills. The collected data was used as descriptive, inferential data which was further analyzed and compared to the pretest and the current collected primary data. The purpose of this study shows the importance of the online assessment literacy and the need of assessment literate trained educators who might support in identifying the training needs of online assessment with help of Bloom's Model in connection with the digital Bloom's taxonomy. As some experienced educators lack the need of literacy training skills in the online assessments, this proposed model would be beneficial for the educators, and could prepare them as future trainers.
\end{abstract}

Keywords: assessment literate educators, digital bloom, need of online assessment training, online assessment literacy, reliable assessments

\section{Introduction}

Assessment literacy is used as a tool that appraises the learners, by assessing the students' understanding, interpreting the assessment results to provide feedback (Evans, 2013). The Assessment (Formative and Summative) process helps in the identification of the effectiveness of the teacher's teaching capabilities along with the students' achievements (Khan et al., 2019). Success of the learner depends on the effective use of the Assessment Literacy (Mellati \& Khademi, 2018). For a school educator, the assessment knowledge, skills and practices are necessary for the preparation of the assessments. Therefore, to maintain the quality of the online assessments, assessment literacy for educators has become an integral part of education system. Due to the 2020 Pandemic outbreak, most of the schools faced number of challenges in teaching, learning and assessments, setting the need to establish online teaching and learning. As a result of this outbreak, the educational institutes closure had affected around 1.5 billion (87\%) of student population (UNESCO, 2020). The history of corona Virus is not old and is known since 1960's, originating from the family of SARS and MERS-Cov (Fielding, 2020). Though UNESCO encouraged the shutdown of the schools; teaching, learning and assessing continued on the online platform (Bender, 2020).

The new normalcy poses the following statement; schools' management might need to plan for future short comings as part of the contingency strategic plan (Scott \& Husain, 2021). Most of the schools have been a victim of the crises, as the 2020 International Results (IB, IGCSE, AS, A level) were quite appalling; it seemed that the schools had never planned out for any setbacks for the pandemic times. However, the need of emergency planning could help in accommodating the new ways of assessing, teaching and learning to facilitate the smooth delivery of the content between the educators and students (Taha et al., 2019).

England's 2020 (Year 11-13) results had almost 36\% of lower grade entries after the exams were cancelled out due to the pandemic, and the exam watchdog Ofqual, called in to review the moderation process where grades 
were altered (Coughlan et al., 2020). It is also imperative for the school Management, to keep up with the changes in the learning styles of the students and provide the necessary online training to the educators, which might further help in enhancing the effectiveness of the educator's online teaching capabilities.

\section{Purpose of Study}

The purpose of this article is to train the trainers as assessments literate educators. Examining the current situation, the use of digital integration in creation of reliable online assessment preparation, this might benefit the schools and the management as part of the in-service training plans. Therefore, by presenting this research, the educators might like to get effectively trained as assessment literate educators to motivate themselves and would also like to challenge their students in order to reach higher order thinking skills (Churches, 2008). This digital Blooms integration of cognitive concept to reach the higher order thinking skills from lower order thinking skills, can support the educators in writing up the reliable online assessments. The school management also might need to take in consideration the need of assessment literate training as part of their professional development plan, which can contribute in updating the schools' curriculum with digital assessments integration. A mixed method research will be conducted which will present the educators' knowledge on assessment skills and practices, where the untrained assessment literature educators' need for the training will be highlighted. This research will explore the need of the untrained educators to be trained as assessment literate educators. As part of the research, the questionnaires will be distributed out to different schools' management administrators and educators. As the online assessment literacy has become important during these pandemic time, because of the need for technological knowledge in today's world, the school can improve teacher technical competency and self-efficacy by putting a focus on professional development along with effective student learning (Scott \& Husain, 2021).

The yearly planned curriculum could be effectively designed for the schools; however, the proper integration of the assessments raises the standards of the learning (Fletcher \& Shaw, 2012), and to prove the effectivity of the curriculum along with good teaching strategies, effective testing is important as well. Proficiency in assessments and evaluation practices could enhance the quality of teaching and learning skills (Volante \& Fazio, 2012). Therefore, reliable assessments make testing effective which can determine the students' achievement to reach the learning outcomes.

\subsection{The Objectives for This Research}

a) To gather assessment data from International exam boards and create inferential analysis to Investigate students' achievement in pandemic 2020 and compare to the previous 2-3 years' record.

b) To investigate online assessment knowledge literacy for teachers.

c) To find the significance of educator's willingness to receive and to train other educators on online assessment literacy.

d) To measure the relationship between the assessment literacy and the need to train on the assessment practice.

\section{Literature Review}

The focus of this research is to present how the online assessment literacy could support in identifying the needs of online assessment with help of Bloom's Model in connection with the digital Bloom's taxonomy. This Model is integrated with Information communication technology tools for the online assessment literate educators to cater to the needs of different ability students (Husain, 2021). The original Bloom's Taxonomy was actually designed for assessment purpose. However, through Bloom's magnifying lenses it was discovered that this can also be used for designing a course and setting up a curriculum (Persaud, 2018). Therefore, according to this research, during these pandemic times the educators could get professionally trained with the online planning, teaching, and learning methods.

Due to the pandemic outbreak, some of the international results were based on the coursework, historical data from the school and the predicted grades, which were internally assessed by the moderators as part of the online assessment school requirements. Furthermore, to measure the success of the educational institute and its stake holders, and to provide guidance for the students' academic success, might depend on the reliability of properly designed online or non-online assessments by the assessment literate educators (Ryan, 2018). For the IB results, there was a decrease in the worldwide average as compared to the previous years, however the results did manage to get slightly adjusted after some of the complaints and petitions raised by the students. The management might take in consideration for setting up the online assessment policies which might set a guidance level that could measure the effectivity of the learner's outcome. 
Therefore, the assessment policies are usually in place with regards to their resources and teaching-learning practices, which forms the basis of student testing for entry to further education (Best et al., 2013). And with the proper rules and policies set for the online assessment literacy training, a model as guidance could benefit the educators to understand the students' assessment abilities during these pandemic times (Husain, 2021).

\subsection{Study Beneficiaries}

This study may be beneficial to the school's management and the teachers, as this will help the school by providing training on the online assessment education with the integration of information technology tools. This study might be useful to the Head of Curriculum and Assessments, Head of School etc. The assessment literate trainers may also benefit the school educators as they can train them further.

\subsection{Importance of Trained Assessment Literate Educators}

Due to the inadequate training, misuse and wrong application of handling the assessments might impact negatively on the students' lives; whether it be for their promotion, graduation or grading. Therefore, looking at the schools' training needs, trained assessment literate educators are highly in demand as educational professionals (Fabry, 2016). Effective integration of online assessments is necessary for the online classrooms to support the curriculum and to monitor students' learning. In order to evaluate, and measure the students' capabilities; effective assessments are set as a reliable tracking tool for the assessment literate educators (Husain, 2021).

For assessment literate educators, creation of reliable online assessments begins with the understanding of the basic concepts (Popham, 2011). Online assessment literacy (Digital Bloom's Model) provides the educators to innovatively design new assessments, reducing the chances of biasness which might place students at disadvantage (Husain, 2021). The proposed model inspired from Benjamin Bloom's Taxonomy (Clark, 2015) and (Churches, 2008), Digital Bloom's Taxonomy may benefit the educators.

\subsection{Online Assessments}

Online assessments do not require pencil-paper option presenting easier online access (Vipin, 2019) by moving on to the electronic version and eliminating the need of traditional style. Teachers might like to get trained on the online assessments practices and set themselves as innovative assessment literate educators. Therefore, in order to challenge the students, and to provide a proper guidance to other inexperienced educators, assessment literate educators might also show interest in providing training needs professionally (Husain, 2021). Though IT integrated are add on tools, there is a chance that students would achieve better with technological integration with proper guidance presented by the educators (Scott \& Husain, 2021).

Innovative educators might like to take up the initiative to be more creative, by utilizing the Digital Bloom's taxonomy effectively and setting an example for a new improved method of online classes and assessments (Bender, 2020), with the integration of ICT applications tools. Digital Bloom's Model might also help the educators to educate and train in creation of reliable online assessment (Husain, 2021).
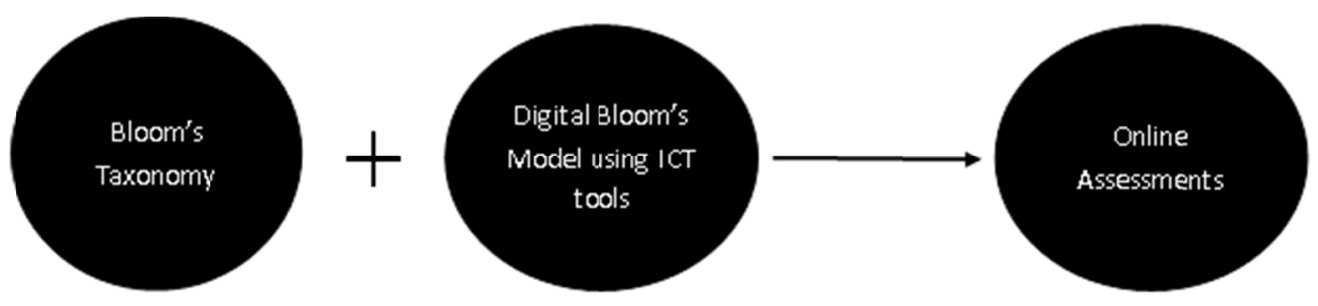

Source: (Husain, 2021)

\subsection{Example of Business Subject}

Jenny is a professional artist; she is looking for a suitable location for her new business.

Question-What factors should think be considered before decision is finalized. (Options by the teacher for the online assessments using offline tools)

1) Option 1: Level I and II: Remembering and understanding: YouTube video (For students to view video and submit their answers as back channeling) 
2) Option 2: Level III, IV, V and VI: Applying, analyzing, Evaluating and creating: Multimedia creation software (To gather an interview to present as a research strategy).

Balance sheet 2001 and 2002

\begin{tabular}{l|l|l}
\hline Items & $2001(\$)$ & $2000(\$)$ \\
\hline Turn over & 20,000 & 18,000 \\
\hline Cost of sales & 12,000 & 10,000 \\
\hline Gross profit & 11,000 & 8,000 \\
\hline Net profit & 4,000 & 3,200 \\
\hline Current assets & 13,000 & 11,000 \\
\hline Current Liabilities & 8,000 & 7,000 \\
\hline Capital employed & 18,000 & 17,000 \\
\hline & & \\
\hline
\end{tabular}

Source: sample created by the researcher

Question-Calculate: Current Ratio for 2000 and 2001(Options by the teacher for the online assessments using online tools)

1) Option 1: Level I and II: Remembering and understanding: Using Kahoot.it (Online application strategy to create quizzes).

2) Option 2: Level I, II and III: Remembering, understanding and Applying: MS. Office (Ms. Excel) using spreadsheet, as offline strategy.

\section{Research Methodology}

This research study is based on the mixed method using qualitative and quantitative analysis. This research is designed to know the significance of assessment literacy and need of assessment literate trainers. The quantitative correlation analysis is used to find the relationship between the assessment literate educators and their willingness to provide a professional development as trainers. The questionnaire titles are segregated into assessment literacy practice, assessments literacy skills, assessment literacy professional development training and need of becoming the trainers as part of qualitative research in order to analyze the significance and its correlation.

As part of the first analysis procedure, a secondary research report, data is collected from the UK and American International board results, which is further analyzed. These results are taken from the past 2-3 years and are compared against the newly 2020 released results, which were based on the online school formative results, predicted grades, historical data instead of the face-to-face final written examinations.

\subsection{Population and Sample}

This research of 32 respondents was collected as part of pilot testing. Their responses were used to test the validity and reliability of the questionnaire. The educators chosen at random from different schools comprised of teachers and administrators such as head of schools, heads of department.

\subsection{Data Collection Tool}

Secondary results collected from the international boards of UK and American Board. The IGCSE, ALEVEL and AS level are from the UK Board and International Baccalaureate is from the American Curriculum. These results were collected from the year 2018 - 2020 for the result analysis report (ALEVEL/AS Level/ IGCSE/ IB level), to check how 2019 and/or 2018 results differed from that of 2020 results.

As a primary research a questionnaire survey was distributed to international school educators comprising of teachers and administrators. The questionnaire was distributed using online google forms. This questionnaire's purpose was to gain an insight of assessment literacy knowledge of the educators.

\subsection{Data Analysis Tool}

The collected data were used to present as descriptive and inferential data analysis using Microsoft Excel. Different advanced functions such as "What if Analysis", "Count if", "Coorel", "t-test", "STDEV.S" and basic formulas such as "Sum", "Average" were used.

The questionnaires were presented to the respondents, where the topics were segregated to count the frequency of the assessment literacy practice and assessments literacy skills as part of qualitative research in order to analyze the significance and its correlation. The Pearson correlation is then based on the frequency count of 
assessment literacy skills and practices by the educators and the school's management. The significance of receiving assessment literacy training and training as PD trainers was also calculated by counting the frequency of receiving the professional development training and need for training others as trainers from the questionnaire as part of qualitative research analysis.

The secondary data was further analyzed by presenting the data as percentages and graphs. The percentage and the graphical representation provided a clear comparison between the overall world averages of different boards from Grade 10/ year 11 to Grade 12/Year 13 results achievements.

The collected data from the online questionnaire responses of 32 respondents were separated as demographics variables as form of frequencies and percentages. The collected responses from the school educators such as the teachers and the management were segregated to compare the teachers or management according to their qualification and their knowledge of assessment literacy or the willingness to train others educators etc. The data collected were used to identify the significance and measure the relationship of assessment literacy and to that of the assessment training.

\section{Findings and Results}

For the first analysis of descriptive and inferential statistics, the world average results were interpreted as form of percentages and graphs to compare the 2020 result score to that of 2019 and/ or 2018.

\subsection{Analysis Before the Research (International Results Analysis)}

The 2020 result inferential data analysis was conducted to compare it with the previous results, in order to show whether the 2020 results were marked up or were the results marked down or were the results able to maintain an average in comparison with the last 2-3 years' analysis.

Table 1. A Level result 2018-2020 Source: Cambridge International AS \& A level

\begin{tabular}{lcccccccccccc}
\hline & \multicolumn{3}{c}{$\mathrm{A}^{*}$} & \multicolumn{3}{c}{$\mathrm{A}$} & \multicolumn{1}{c}{$\mathrm{B}$} \\
\hline Year & 2020 & 2019 & 2018 & 2020 & 2019 & 2018 & 2020 & 2019 & 2018 & 2020 & 2019 & 2018 \\
ACCOUNTING & 10.6 & 5.9 & 5.1 & 23.9 & 11.8 & 12 & 39.8 & 21.4 & 20.6 & 57.2 & 35.6 & 35 \\
BIOLOGY & 8.5 & 9.8 & 10.3 & 21.3 & 23.7 & 23.9 & 37 & 39.1 & 39.4 & 59.5 & 55.8 & 56.1 \\
BUSINESS & 4.3 & 1.7 & 2.2 & 16.6 & 5.8 & 5.9 & 32 & 13.2 & 13.1 & 51.2 & 28.1 & 28.5 \\
CHEMISTRY & 11.3 & 12.2 & 12.3 & 24.2 & 22.8 & 23.5 & 39.4 & 36 & 36.5 & 58.7 & 51.9 & 52.4 \\
MATH & 8.3 & 8.3 & 7.1 & 23.1 & 22.2 & 22.9 & 43.2 & 37 & 37.7 & 64.7 & 55.9 & 56.2 \\
PHYSICS & 10.7 & 9.4 & 9.9 & 23.8 & 20 & 21.2 & 39 & 34.1 & 35.9 & 59.9 & 51.4 & 51.6 \\
\hline
\end{tabular}
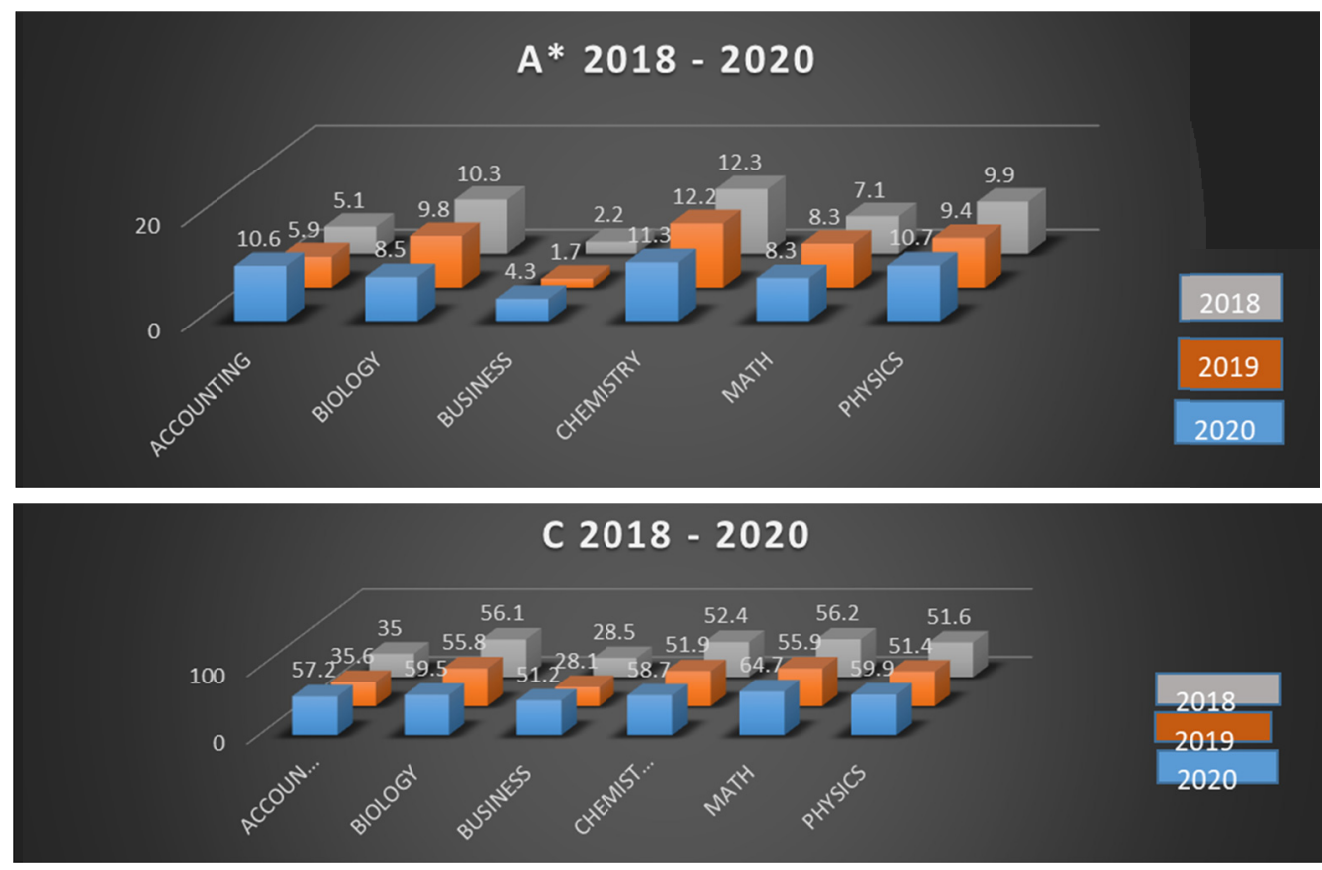

Figure 1. A Level result 2018-2020 
Table 2. AS Level result 2019-2020 Source: Cambridge International AS \& A level

\begin{tabular}{ccccccc}
\hline & A 2020 & 2019 & B 2020 & 2019 & C 2020 & 2019 \\
\hline ACCOUNTING & 28.6 & 18.2 & 39.8 & 32.6 & 52.5 & 48.8 \\
BIOLOGY & 22.8 & 26.8 & 38.2 & 44.4 & 53.1 & 60.7 \\
BUSINESS & 14.9 & 8.9 & 30.8 & 18.9 & 46.4 & 33.3 \\
CHEMISTRY & 24.4 & 29.2 & 35.6 & 49 & 50 & 63.6 \\
MATH & 22.7 & 27.4 & 39.3 & 41.4 & 59.6 & 59.4 \\
PHYSICS & 24.4 & 28.8 & 36 & 49.2 & 54.6 & 64.2 \\
\hline
\end{tabular}
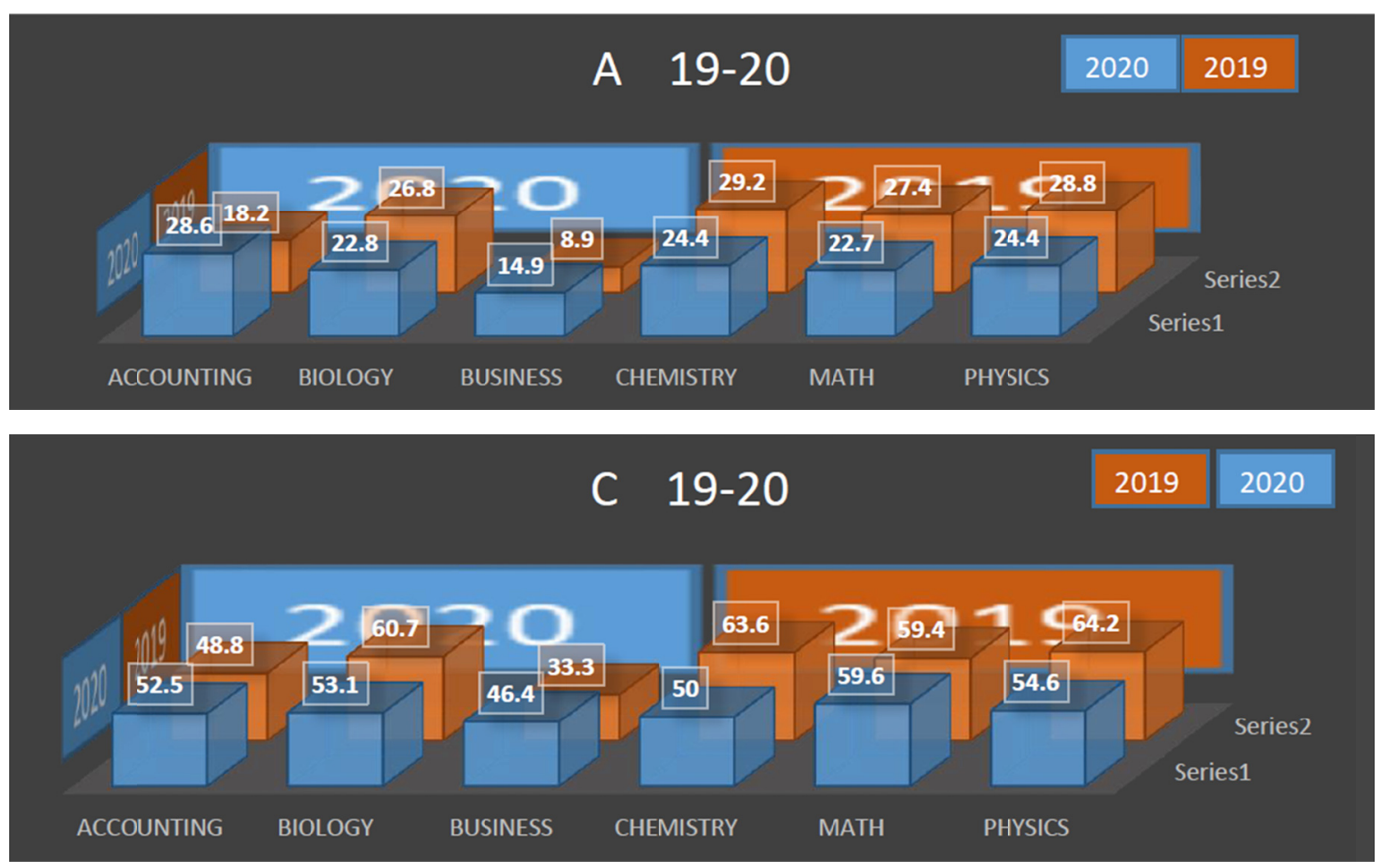

Figure 2. AS Level result 2019-2020

Table 3. IGCSE result 2018-2020 (Source: Cambridge IGCSE Results Statistics)

\begin{tabular}{|c|c|c|c|c|c|c|c|c|c|c|c|c|}
\hline \multirow{2}{*}{ IGCSE LEVEL } & \multicolumn{3}{|c|}{$\mathrm{A}^{*}$} & \multicolumn{3}{|c|}{$\mathrm{A}$} & \multicolumn{3}{|c|}{$\mathrm{B}$} & \multicolumn{3}{|c|}{$\mathrm{C}$} \\
\hline & 2020 & 2019 & 2018 & 2020 & 2019 & 2018 & 2020 & 2019 & 2018 & 2020 & 2019 & 2018 \\
\hline ACCOUNTING & 16.6 & 14.9 & 19.6 & 39 & 40.7 & 38.1 & 58.3 & 60.6 & 58.2 & 77.8 & 78.8 & 78.2 \\
\hline BIOLOGY & 29.6 & 25 & 9.6 & 48.9 & 47.2 & 24.3 & 64.7 & 65.3 & 42.4 & 80.7 & 81 & 65.9 \\
\hline BUSINESS & 19.3 & 15.3 & 3 & 38.3 & 38 & 10.6 & 59 & 61 & 25.9 & 77.7 & 77.9 & 49 \\
\hline CHEMISTRY & 26.9 & 24.5 & 16.5 & 51.7 & 52.2 & 35.9 & 68.6 & 68.9 & 55.4 & 84.4 & 84 & 75.8 \\
\hline MATH & 19.2 & 21.5 & 7.5 & 39 & 40.6 & 20.3 & 57.5 & 61.6 & 34.5 & 78.9 & 79.9 & 61.1 \\
\hline PHYSICS & 27.4 & 29.4 & 17.9 & 51.9 & 51.6 & 35.5 & 68.7 & 69.5 & 55.9 & 83.2 & 83.4 & 75.3 \\
\hline
\end{tabular}



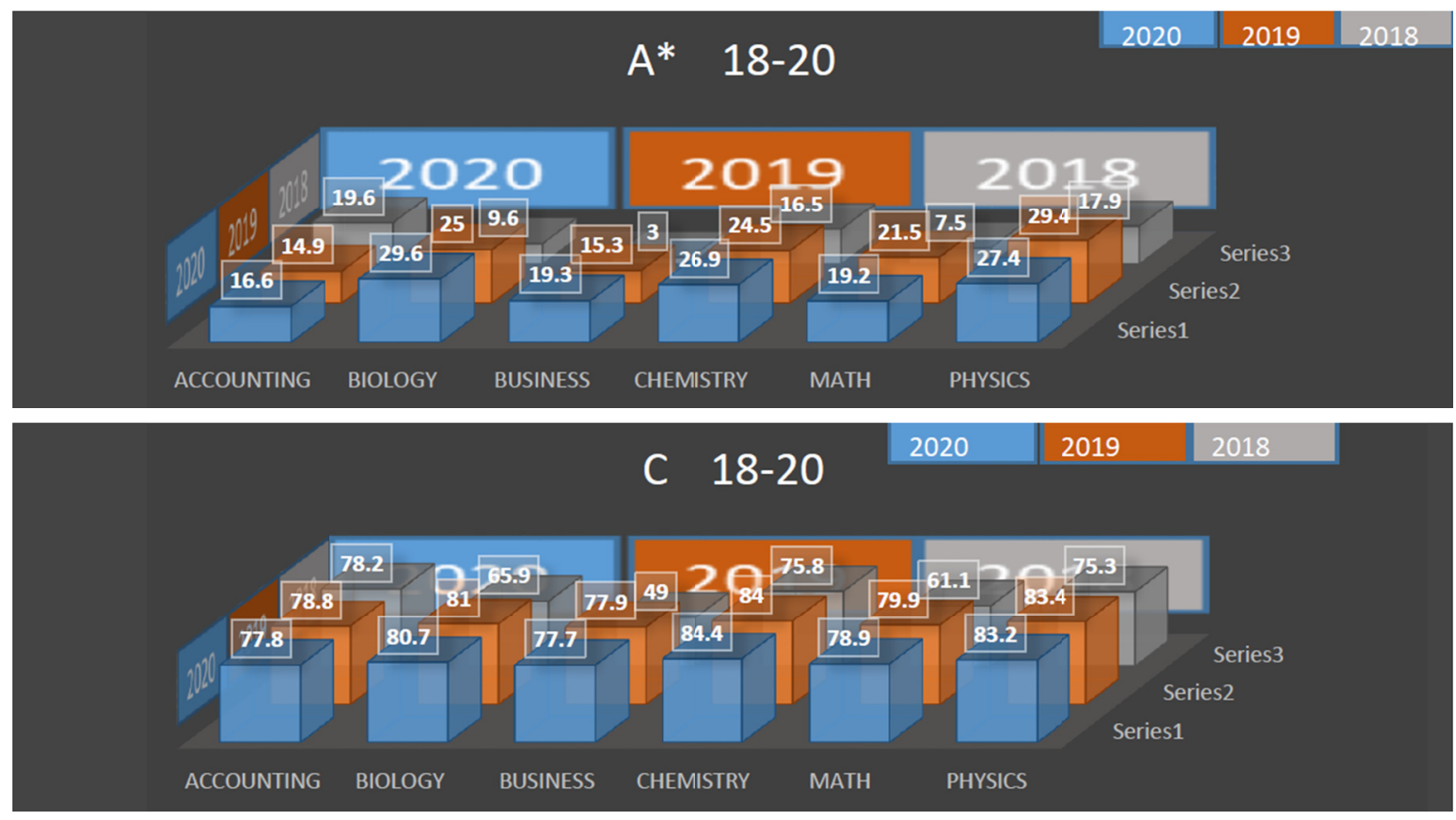

Figure 3. IGCSE result 2018-2020

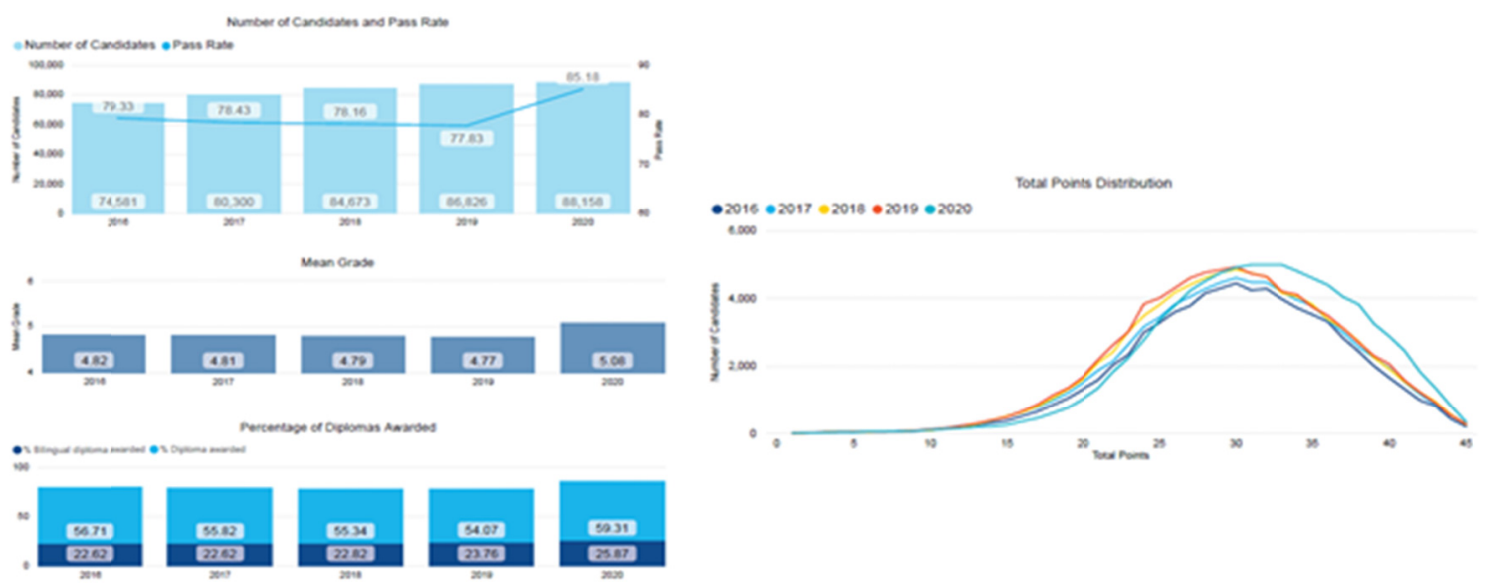

Figure 4. IB: IB Level result 2018-2020 (Source: IB Diploma Programme Final Statistical Bulletin: May 2020 Assessment session)

Looking at the results year 2020, the world-wide averages for the international boards, subjects' score can be seen either increased or pulled down. Table 1 and Figure 1 illustrate the results from 2018-2020 comparison. Accounting and Business score doubled with A level, however with the AS level students' performance for grade "A", was much better as compared to the other subjects, Table 2 and Figure 2 as the results had doubled, but the grade "B's and "C's" were moderately effected. A Level result for the Sciences and Math were almost similar in comparison with the previous grades (Figure 1) and for the AS level results the scores had been seen with minor fluctuation (Figure 2). Table 3 illustrates the IGCSE's results with minor fluctuation and for few scores the scores were hardly affected.

Figure 4IB illustrates the IB results comparison. The worldwide averages for overall pass rate for 2019 represents $77.83 \%$ and $85.18 \%$ for year 2020 . The mean score had increased from $4.77(2019)$ and $4.79(2018)$ to $5.08(2020)$.

\subsection{Analysis of the Primary Research}

The primary research conducted with the educators and the management shows the inferential and descriptive analysis of the assessment literacy and the need of the training regarding the online assessment. The 
demographic data is presented in form of frequencies and percentages, representing the qualification and whether or not they had received assessment literacy training, which could also affect the online teaching, learning and assessment.

Table 4. Survey collection table: educators qualification and whether or not trained for assessment literacy (al) in figures and percentages

\begin{tabular}{ccccccc}
\hline Qualification & & $\%$ & Not AL Trained & $\%$ & Yes AL Trained & $\%$ \\
\hline M.A. & 7 & 21.87 & 5 & 29.41 & 2 & 13.33 \\
B.A. & 13 & 40.62 & 5 & 29.41 & 8 & 53.33 \\
M.S.Ed.D. & 2 & 6.25 & 2 & 11.76 & 0 & 0 \\
B.S. & 7 & 21.87 & 3 & 17.65 & 4 & 26.66 \\
M.S. & 1 & 3.13 & 1 & 5.88 & 0 & 0 \\
Not on the list & 2 & 6.25 & 1 & 5.88 & 1 & 6.67 \\
Total & 32 & 100 & 17 & 100 & 15 & 100 \\
\hline
\end{tabular}

In the above table, the highest number representing $53 \%$ are with B.A qualification and around $26 \%$ respondents with the B.S. qualification out of 32 have been trained in assessment literacy. However, with the Master's degree there are none and $6 \%$ represents with unknown or not on the list qualification. Table 5 illustrates the further segregation of their working experience that the 13 administrators with $40 \%$ of $1-5$ years of experience where $50 \%$ have been working as teachers in the same range of years.

Table 5. Survey collection table-educators number of experience as teachers and management administrators

\begin{tabular}{cccccc}
\hline ADMIN & & $\%$ & TEACHER & & $\%$ \\
\hline 16-20 years & 1 & 3.125 & $16-20$ years & 3 & 9.375 \\
11-15 years & 1 & 3.125 & $11-15$ years & 4 & 12.5 \\
6-10 years & 0 & 0 & $6-10$ years & 7 & 21.875 \\
1-5 years & 13 & 40.625 & $1-5$ years & 16 & 50 \\
none of the above & 17 & 53.125 & none of the above & 1 & 3.125 \\
25-30 years & 0 & 0 & $25-30$ years & 0 & 0 \\
21-25 years & 0 & 0 & 21-25 years & 0 & 0 \\
more than 30 years & 0 & 0 & more than 30 years & 1 & 3.125 \\
& 32 & 100 & & 32 & 100 \\
\hline
\end{tabular}

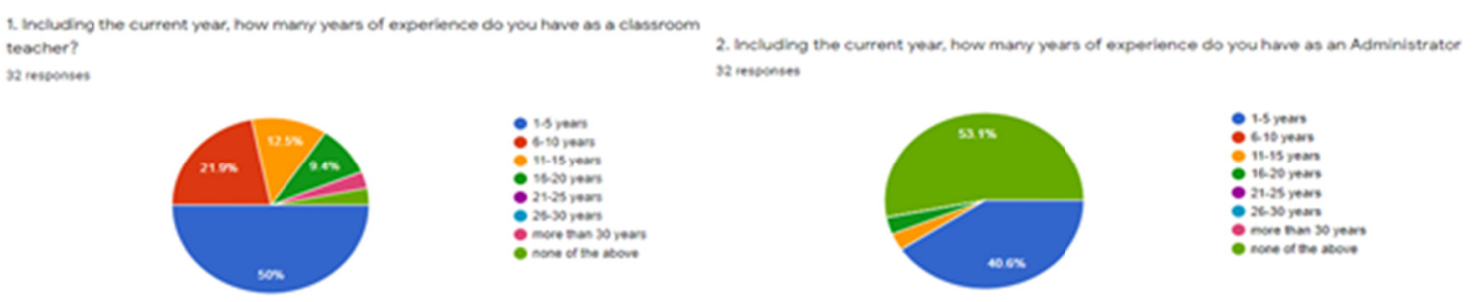

Figure 5. Survey collection graph-educators number of experience as teachers and management administrators

Where the $68 \%$ of these experienced educators have shown interest stating that the students should be tested on both (formatives and summative) the assessments during the online teaching and learning phase as it gives a clear picture of the students' performance, but $25 \%$ disagreed to only setting online formatives assessments as the feel that the students might not perform well if the students score low on the summative due to fear factor, or not taking the summative seriously, represented in Table 6 and Figure 6. 
Table 6. Survey collection table-educators acceptance of formatives or summative during online assessment

\begin{tabular}{ccc}
\hline & & $\%$ \\
\hline Summative & 2 & 6.25 \\
Formative & 8 & 25 \\
Both & 22 & 68.75 \\
& 32 & 100 \\
\hline
\end{tabular}

Further taking to the next level of why the online assessments are important and the reason that the educators might need to get trained in the online assessment literacy, the standard deviation sample calculated to find the significance and correlation of assessment literacy. The t-test shows that $2-\mathrm{E}_{18}$ significance on assessment literacy and practice is calculated and 0.8127 significance on educators willing to receive training and train others as online assessment literate educators. To test this significance against 0.05 or .01 alpha, as stated the sample size is low, the score of significance is quite low. Where the correlation between the assessment literacy and train as assessment literate educators come around to 0.68 which shows a moderate relationship good enough to prove that Educators as teachers or management showing interest as they want to progress and making sure that the students are receiving proper online teaching and learning and prepared for reliable online assessments (table 7).

Table 7. Survey collection table-t test significance and correlation

\begin{tabular}{cc}
\hline significance of receiving Assessment literacy training and training as PD trainers & 0.812 \\
Significance test of assessment literacy skills and practice & 0.00 \\
PEARSON COORELATION $\mathrm{r}=$ & 0.68 \\
\hline
\end{tabular}

\section{Discussion}

As per the findings of the pretests which had led to the further research, the fluctuation in the 2020 academic results lead the students all around the world that they had felt cheated, as 17,000 students had signed a petition stating the injustice in the grading system. The IB grades had gone significantly low than what had been predicted and had sent for the final moderation reported as per the Inside Higher Ed report. However, the IB defended itself stating the fact that the average rouse from 29.62 to 29.90 for the year 2020 (Jaschik, 2020).

The primary research findings revealed that there are qualified and experienced teachers and school administrators with bachelors' and masters' degree, however; they lack the online assessment literacy skills. The highest percentage of the educators believe in testing the students with properly designed online formatives and summative; as the students' confidence level, emotions, ethics and their behavior gets affected either in positive or negative aspect. The experienced teachers and administrators possess the understanding of the Bloom's framework, but some of the educators lack the application process in the online assessment strategies. Furthermore, they have shown interest in receiving the necessary training requirements.

\section{Conclusion}

The year 2020 has taught an imperative lesson that students need to be well assessed with reliable online assessments. Due to the ongoing pandemic crises, the educators need to be trained as the assessment literate educators, with information communication technology tools integration using the Digital Bloom's Model. This research reveals that some experienced educators lack the need of online assessment literacy training skills and are inclined towards getting trained and would further develop the importance of online assessment literacy by educating others.

\section{Recommendation}

The fact cannot be neglected that educators need to be trained as online assessment literate educators'. The school management might need to think about an online assessment literacy Model built on the framework such as Digital Bloom to cater to the needs of the students. As the students are equipped with different learning abilities, and according to the Bloom's Taxonomy Model, teaching and learning has been made easy for the educators and the professional development trainers. Bloom's Taxonomy caters to the different needs taking in consideration of critical thinking skills and future researchers might be interested in designing a model with the integration of Digitally designed Assessments which also caters to the needs of educators in the preparation of reliable online assessments. The schools' Training plans might need to accommodate the online Assessment 
Literacy as part of the professional development program which can benefit the educators and the school administrators. The online assessment practices are also recommended for the student educators in the field of Educational degree level program. The Ministry of Education can initiate online assessments training courses to train the trainers regarding the online assessment literacy practices.

\section{References}

Bender, L. (2020). Key messages and actions for Covid-19: Prevention and control in school.

Best, M., Knight, P., Lietz, P., Lockwood, C., Nugroho, D., \& Tobin, M. (2013). The impact of national and international assessment programmes on education policy, particularly policies regarding resource allocation and teaching and learning practices in developing countries. Final report. London: EPPI-Centre, Social Science Research Unit, Institute of Education, University of London.

Churches, A. (2008). Bloom's digital taxonomy. Bloom's revised digital taxonomy.

Clark, D. (2015). Bloom's Taxonomy: The affective domain: Big dog \& little dog.

Coughlan, S., Sellegren, K., \& Burns, J. (2020). A-levels: Anger over 'unfair' results this year.

Evans, C. (2013). Making Sense of Assessment Feedback in Higher Education. Review of Educational Research, 83(1), 70-120. https://doi.org/10.3102/0034654312474350

Fabry, D. (2016). Why we need assessment literacy as part of teacher preparation. Assessment Basics.

Fielding, B. C. (2020). A brief history of the coronavirus family - including one pandemic we might have missed.

Fletcher, A., \& Shaw. G. (2012). How does student-directed assessment affect learning? Using assessment as a learning process. International Journal of Multiple Research Approaches, 6(3), 245-263. https://doi.org/10.5172/mra.2012.6.3.245

Husain, F. N. (2021). Use of digital assessments how to utilize Digital Bloom to Accommodate Online Learning and Assessments? Asian Journal of Education and Training, 7(1), 30-35. https://doi.org/10.20448/journal.522.2021.71.30.35

International Bacalaureate. (2020). IB Diploma Programme Final Statistical Bulletin: May 2020 Assessment session. IB Global Centre Cardiff.

Jaschik, S. (2020). What's wrong with this year's IB scores.

Khan, N. F., Hussain, S., \& Imad, M. (2019). Classroom assessment, literacy and practice of teachers educators in Pakistan: Global Social Sciences Review (GSSR). Research Gate. https://doi.org/10.31703/gssr.2019(IV-IV).07

McGee, P. (2013). Supporting academic honesty. Journal of Educators online, 10(1), 1-31. https://doi.org/10.9743/JEO.2013.1.6

Mellati, M., \& Khademi, M. (2018). Exploring Teachers' Assessment Literacy: Impact on Learners' Writing Achievements and Implications for Teacher Development. Australian Journal of Teacher Education, 43(6). https://doi.org/10.14221/ajte.2018v43n6.1

Persaud, C. (2018). Bloom's Taxonomy: The ultimate guide. Retrieved from https://tophat.com/blog/blooms-taxonomy

Popham, W. J. (2011). Assessment literacy overlooked: A teacher educator's confession. The Teacher Educator, 46(4), 265-273. https://doi.org/10.1080/08878730.2011.605048

Ryan, K. A. (2018). An investigation of pre-service teacher assessment literacy: Measure development and Edtpa performance ( $\mathrm{Ph} . \mathrm{D}$ theses, Kent University).

Scott, T., \& Husain, F. N. (2021). Textbook Reliance: Traditional Curriculum Dependence Is Symptomatic of a Larger Educational Problem. Journal of Educational Issues, $7(1), 233$. https://doi.org/10.5296/jei.v7i1.18447

Taha, M., Abdalla, M., Wadi, M., \& Khalafalla, H. (2020). Curriculum delivery in Medical Education during an emergency: A guide based on the responses to the COVID-19 pandemic. MedEdPublish, 9(1), 69, https://doi.org/10.15694/mep.2020.000069.1

UNESCO. (2020). Alternative solution to school closure in Arab countries to ensure that learning never stops.

Vipin, S. (2019). The impact of online assessments on the educational sector. Educational Technology. elearning Industry. 
Volante, L., \& Fazio, X. (2012). Exploring teacher candidates' assessment literacy: Implications for teacher education reform and professional development. Canadian Journal of Education, 30(3), 749-770. https://doi.org/10.2307/20466661

\section{Appendix A}

\section{Questionnaire, for complete proof}

Email:

1. Including the current year, how many years of experience do you have as a classroom teacher?

- $1-5$ years

- $6-10$ years

- $11-15$ years

- $16-20$ years

- $21-25$ years

- 26 - 30 years

- more than 30 years

- None of the Above

2. Including the current year, how many years of experience do you have as an Administrator?

- $1-5$ years

- $6-10$ years

- $11-15$ years

- $16-20$ years

- $21-25$ years

- $26-30$ years

- more than 30 years

- None of the Above

3. Which best describes the educational level you have attained?

- B.A.

- B.S.

- M.A.

- M.S. Ed. D.

- Ph.D

4. To the best of your knowledge, did you take a stand alone course in classroom assessment literacy as part of your teaching or administration preparation program?

- Yes

- No

5. As per your opinion what is the best method of the online assessment that you would consider during these pandemic times?

- Formatives assessments

- Summative Assessments

- Both

\begin{tabular}{|c|c|c|c|c|c|}
\hline & $\begin{array}{l}\text { Please rank how much you personally agree or disagree with the following statements on a scale of } 1 \text { to } 4 . \\
\text { 1: Strongly Disagree 2: Disagree 3: Agree 4: Strongly Agree }\end{array}$ & 1 & 2 & 3 & 4 \\
\hline 6. & $\begin{array}{l}\text { How would you rate your capability (Confidence Level) with the online assessment planning as part of your Online } \\
\text { teaching, learning and assessment strategy. }\end{array}$ & & & & \\
\hline 7. & $\begin{array}{l}\text { How would you rate your understanding on the application of the usage of learning objective model such as of } \\
\text { Bloom's or Marzano's frame work? }\end{array}$ & & & & \\
\hline 8. & $\begin{array}{l}\text { How would you rate your level of interest in receiving a professional development training as an Assessment Literate } \\
\text { Educator? }\end{array}$ & & & & \\
\hline 9. & $\begin{array}{l}\text { To what level do you agree that the level of students' achievement is based on the understanding and whether or not } \\
\text { the objectives were attained. }\end{array}$ & & & & \\
\hline
\end{tabular}


10 To what level do you agree that the level of students' achievement can be judged on mostly on setting highe percentage on the formative assessments than the summative.

11. To what level do you agree that according to your experience during these pandemic times, students' performance on the online formative tests score is no different from that of the formatives taken in face to face class assessments.

12. How would you rate your level of confidence with the integration of Information Technology skills in preparation of the activities during the online teaching and learning?

13. How would you rate your level of confidence with the integration of Information Technology skills in creation of the activities during the online assessments?

14. To what level do you agree that all educators should be trained with the online assessment preparation; including the proper use and integration of Information Technology tools.

15. If you were given a chance in future to train other educators, what level of interest would you present as an Assessment literate trainers for your own school and/or outsiders.

16. To what level do you think that the school management focuses on the completion of the curriculum on time and also encourages the teachers to do the same.

How would you rate this statement that Students' scores on their final test as a Summative-Final exams are sometimes

17. inconsistent with their performances on classroom assessments (Ongoing e.g., teacher tests or other in-class activities). The reason for such discrepancies occur due to students' fear factor as some students tend to freeze up on the Summative tests.

How would you rate this statement that Students' scores on their final test as a Summative-Final exams are sometimes inconsistent with their performances on classroom assessments (Ongoing e.g., teacher tests or other in-class activities). The reason for such discrepancies occur due to the students often take summative tests less seriously than they take the formative classroom assessments.

How would you rate this statement that Students' scores on their final test as a Summative-Final exams are sometimes

19. inconsistent with their performances on classroom assessments (Ongoing e.g., teacher tests or other in-class activities). The reason for such discrepancies occur due to the students see the summative tests as means to recall of information while the formative classroom assessments measure more complex thinking.

How would you rate this statement that Students' scores on their final test as a Summative-Final exams are sometimes inconsistent with their performances on classroom assessments (Ongoing e.g., teacher tests or other in-class activities). The reason for such discrepancies occurs due to students' low level of confidence which affects their performance on the Summative tests.

\section{Copyrights}

Copyright for this article is retained by the author(s), with first publication rights granted to the journal.

This is an open-access article distributed under the terms and conditions of the Creative Commons Attribution license (http://creativecommons.org/licenses/by/4.0/). 